\title{
A Volatile Substance Controlling Early Stages of Zygospore Formation in Rhizopus sexualis
}

\author{
By PAMELA M. HEPDEN* AND LILIAN E. HAWKER \\ Department of Botany, University of Bristol
}

(Received 2 August 1960)

\begin{abstract}
SUMMARY
The inhibitory effect of low temperature $\left(c .10^{\circ}\right)$ on initiation and early development of zygospores of Rhizopus sexualis is less severe in mature cultures (in which numerous zygospores have already been formed before transfer to the low temperature) than in young ones. The severe effect of low temperature on immature cultures is not counteracted by any of a number of known growth substances, by extracts of mature mycelium and zygospores, or by used culture media. The effect of mature cultures in counteracting low temperature inhibition of zygospore production in young ones is able to pass across a gap of $5 \mathrm{~mm}$. between the cultures and must therefore be due to a volatile substance (or substances) produced by the mature mycelium. By the use of small chambers which allow young test cultures to be kept at $10^{\circ}$ while a stream of air from mature ones growing at $20^{\circ}$ passes over them, it is confirmed that the active factor is volatile. This substance is not carbon dioxide or ammonia and is basic in nature. Its probable identity is discussed and comparison is made with some other volatile substances reported to influence growth and development of fungi.
\end{abstract}

\section{INTRODUCTION}

The initiation and early development of zygospores of Rhizopus sexualis (Smith) Callen and of some other members of the Mucorales are prevented by temperatures of $10^{\circ}$ or lower (Hawker, Hepden \& Perkins, 1957). Zygospores which have reached a later stage of development before being subjected to the low temperature continue to develop and eventually reach maturity. Growth of mycelium and sporangia also continues slowly at these low temperatures. Hawker et al. (1957) concluded that the inhibition of the early development of zygospores is due to ' a temperatureinduced block in the synthesis of some substance or substances essential to further development, or to a slowing up of translocation of such substances into the gametangia from the supporting hyphae'. Occasionally young spores continue to develop in a colony exposed to the critical low temperature when older zygospores are also present. This effect might be due to the presence in relatively old cultures of a reserve of the hypothetical stimulatory substance, the synthesis of which is inhibited by low temperature.

* Mrs K. W. Joy ; present address : Dept. of Botany, Sir John Cass College, London. 


\section{METHODS}

The experimental methods were generally similar to those described in the previous paper (Hawker et al. 1957). Special methods will be described in the appropriate places in the text.
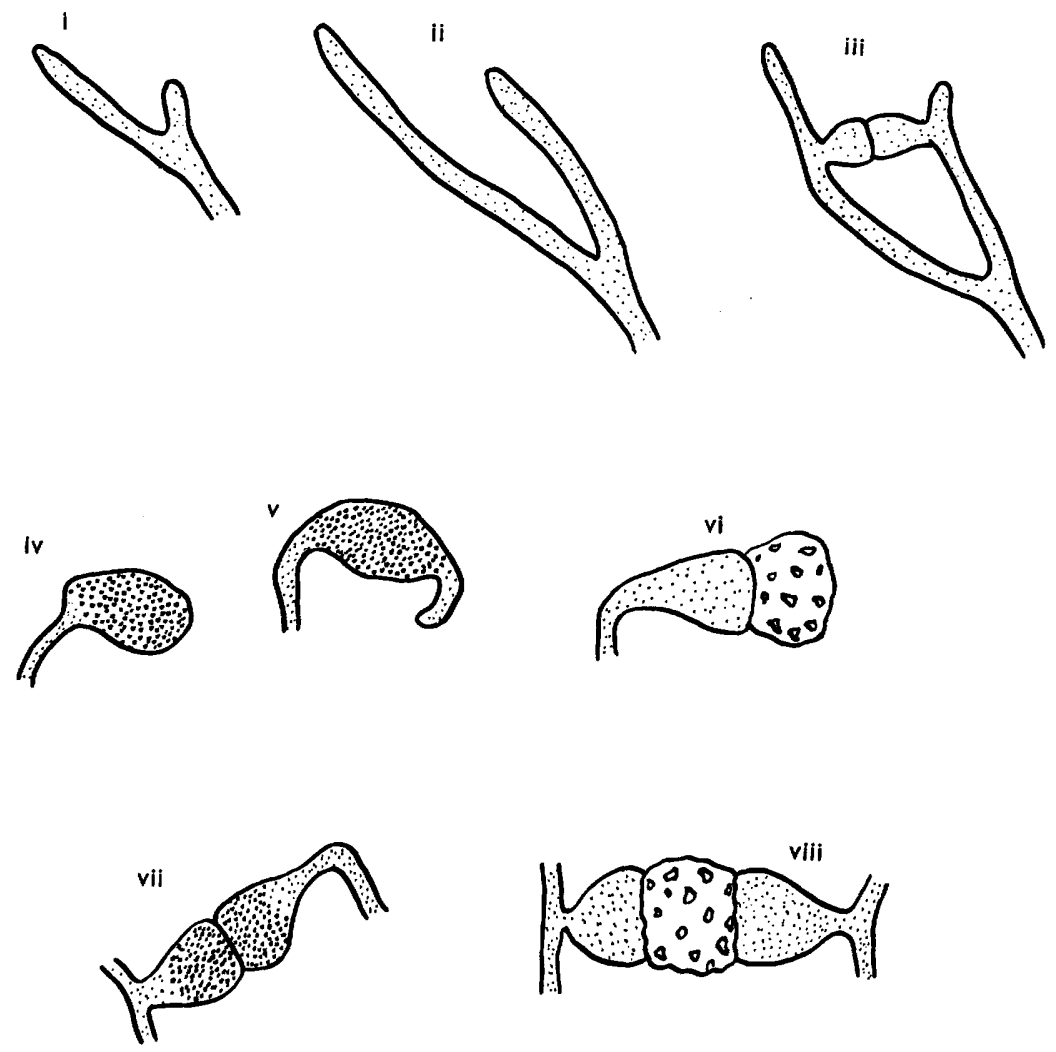

Fig. 1. Normal and abnormal development of zygospores of $R$. sexualis. i, ii, stages in formation of zygophores; iii, production of normal conjugating progametangia from zygophores; iv and v, pseudophores (or abnormal progametangia); vi, azygospore developing from a pseudophore; vii and viii, further development of normal zygospore (for comparison with pseudophore and azygospore). Diagrammatic.

In the earlier paper intensity of reproduction was expressed as the zygospore index (ZI) which was calculated from the numbers of zygospores at various defined stages of development in arbitrarily chosen microscopic fields. In the present investigation the differences were small and the zygospores were not uniformly distributed over the colony so that the use of the zygospore index was not always appropriate. Alternatively, results were expressed as total numbers of zygospores or average number in particular microscopic fields. In many experiments, however, zygospores were not formed, but the zygospores developed swellings (termed pseudophores by Callen (1940)) which have been interpreted as potential progametangia (Fig. 1) or which occasionally develop into azygospores. No method was devised to measure the frequency of these. 


\section{Zygospore formation in Rhizopus}

The culture used in early experiments was that used throughout the work described in the previous paper. During the present investigations, however, this isolate became variable and showed a general tendency to be less fertile and to produce an increased proportion of azygospores. Through the kindness of Dr Kiyosi Kominami of Tokyo, a new isolate was obtained which was used in all later experiments. The behaviour of this Japanese isolate was similar to that of the original one before the latter deteriorated.

\section{RESULTS}

\section{Effect of natural extracts and known growth-promoting substances}

Used media and extracts of mycelium. Culture media in which Rhizopus sexualis or other fungi had been grown were strained to remove mycelial debris, sterilized by autoclaving or by filtration and solidified with agar. When these used media were re-inoculated with $R$. sexualis growth was sometimes poor and in no example was there any counteraction of the inhibitory effect of low temperature.

Zygospore-bearing mycelium of Rhizopus sexualis and of some other members of the Mucorales was homogenized in a small volume of sterile distilled water. Extracts of the homogenate or of the used culture medium were concentrated (i) by evaporation under reduced pressure at $\mathbf{2 5}^{\circ}$, (ii) by rapid evacuation and storage in vacuo at low temperature, or (iii) by freezing and removal of ice crystals. These extracts were added to malt agar plates, either by incorporation in the medium or by placing known volumes in holes cut from the agar after the plates had been poured. Again no counteraction of the inhibitory effect occurred.

Extracts of other natural materials. Rhizopus sexualis was grown on extracts of malt (from 1.0 to $3.0 \%$ ), potatoes, carrots, raisins, prunes and yeast, either alone or supplemented with nutrient solutions, in liquid form or in media solidified with agar. Only on carrot extract agar was the inhibition at low temperature modified; a few new zygospores were initiated on this medium after transfer to low temperature. In a typical experiment the zygospore index (calculated from twelve arbitrarily chosen microscopic fields in each of three plates) was 46 on $1 \%$ malt extract agar and 157 on carrot agar after $50 \mathrm{hr}$. at $20^{\circ}$. After a further $72 \mathrm{hr}$. at $7^{\circ}$ these figures rose to 48 and 200 , an increase of approximately 4 and $22 \%$, respectively.

Since carrot contains a number of vitamins it was possible that one or more of these was responsible for the stimulation.

Pure vitamins. A number of vitamins (thiamine, riboflavin, nicotinic acid, pyridoxin, pantothenic acid, cobalamin $\left(\mathbf{B}_{12}\right)$ and biotin), which are known to influence growth and sporulation of certain micro-organisms, were added to cooling malt extract agar or glucose asparagine agar (glucose, $10 \mathrm{~g}$; ; asparagine, $\mathbf{2}$ g.; $\mathbf{K H}_{2} \mathbf{P O}_{4}$ 1.75 g.; $\mathrm{MgSO}_{4}, \mathbf{0} \cdot 175 \mathrm{~g}$.; distilled water, 1 1.). In other experiments known volumes of solutions of the vitamins were placed in holes cut in plates of agar media in advance of the margin of a growing colony of Rhizopus sexualis. None of the vitamins tested, with the exception of $B_{32}$, decreased the inhibitory effects of low temperature. When a number of zygospores were already present prior to chilling, zygospore initiation continued for a limited time at low temperature when $\mathbf{B}_{\mathbf{1 2}}$ was supplied, i.e. the effect of the presence of mature zygospores was enhanced, but not replaced, by this vitamin. 
Purines. Robbins \& Kavanagh (1942) showed that, for the production of mature zygospores, Phycomyces blakesleeanus requires an external supply of hypoxanthine in addition to the thiamin needed for mycelial growth. This result was confirmed.

Accordingly the effects of purines on Rhizopus sexualis were investigated. In preliminary experiments (Hawker, 1957) there was some evidence that adenine, hypoxanthine and guanine, when added to malt agar or to glucose asparagine agar, increased the rate of growth and of zygospore formation in $R$. sexualis at $20^{\circ}$. Furthermore, these purines showed a partial counteraction of the inhibitory effect of low temperature. In later experiments no such effect could be consistently demonstrated. The experiments were repeated many times by a variety of methods and with a wide range of concentrations of the purines, but the results with $R$. sexualis were usually negative. In a few experiments, in which the source of nitrogen was an inorganic salt, some stimulatory effect of low concentrations of purines occurred. This might be attributed to the use of these as a source of organic nitrogen and not necessarily to a specific stimulatory effect on zygospore initiation.

\section{The effect of the presence of mature living mycelia and zygospores}

The stimulatory effect on young colonies of old ones in close contact with them. Since used culture media, mycelial extracts and known growth-promoting substances did not replace mature living zygospores as a means of counteracting the low temperature effect, the influence of old cultures in close contact with young ones was studied. Segments were cut from agar plate cultures in advance of a young colony and were replaced by segments from older colonies of the same or different species. The plates were then placed at $7-10^{\circ}$. Zygospores continued to develop in such colonies. In a typical experiment the numbers of mature zygospores per microscopic field were 6.7 in the sector nearest the inserted segment of the mature colony and $2 \cdot 6$ in the rest of the young colony. No zygospores developed in comparable young colonies in the absence of the mature segment.

In other experiments an old colony of Rhizopus sexualis, or of a zygosporeproducing species of the homothallic genus Zygorhynchus, growing on malt agar, was covered with boiled cellophane over which cool fresh medium was poured. The fresh medium was then inoculated with $R$. sexualis. This method also resulted in the initiation and development of a few zygospores at temperatures below that permitting spore formation in young colonies in the absence of older ones.

These results are consistent with the supply by the mature cultures of small amounts of an essential metabolite, the synthesis of which is prevented by low temperatures. Since this hypothetical substance was lacking in used culture media and mycelial extracts, it must be unstable, or volatile, or both. Attempts were made to detect the presence of such volatile substances.

The stimulatory effect on young colonies of old ones not in contact with them. The segment transfer experiments were repeated but with gaps left between the agar media on which the young (test) colony and the old (source) colony were growing. When this gap was not more than $5 \mathrm{~mm}$. there was some counteraction of the effect of low temperature on zygospore initiation in the young test culture. Since the stimulus could pass over a gap of $5 \mathrm{~mm}$. it is likely to be due to a volatile substance formed by the old colony. 
Zygospore formation by Phycomyces blakesleeanus is not inhibited at $7^{\circ}$ (Hawker et al. 1957). Segments of this fungus used as a source colony, without contact, induced initiation and maturation of a number of zygospores in young colonies of Rhizopus sexualis at that temperature.

Slide cultures of Rhizopus sexualis supported on glass rods over older agar plate cultures of the same or other species also produced a few zygospores at low temperature.

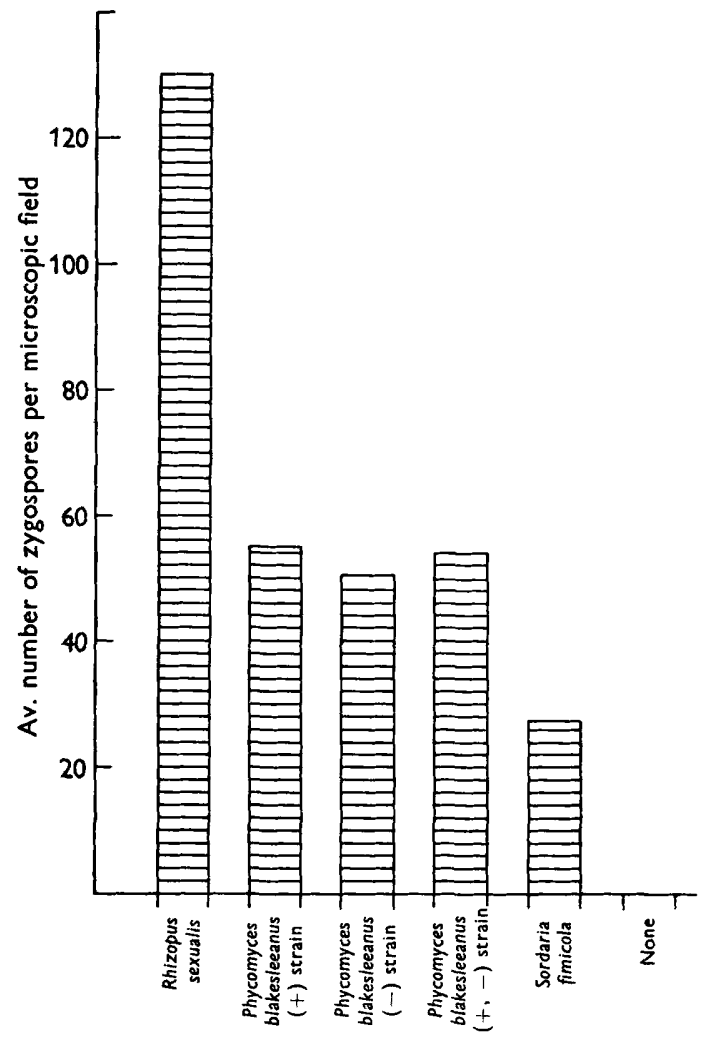

Fig. 2. The effect of volatile products of living fungi on zygospore production by $\boldsymbol{R}$. sexualis. Each block represents the number of zygospores produced by $\boldsymbol{R}$. sexualis in the presence of volatile substances from living cultures of the fungi indicated at base of diagram.

Stimulatory effects also occurred at a temperature of $20^{\circ}$ which is near the optimum for Rhizpous sexualis. Figure 2 shows the number of zygospores in slide cultures supported over living cultures of $R$. sexualis, Phycomyces blakesleeanus and a Pyrenomycete (Sordaria fimicola) and in control slide cultures (supported over sterile plates of agar). In control cultures a number of aerial hyphae (stolons) developed before any zygophores were produced, but in treated cultures the firstformed aerial hyphae were zygophores. Zygospore production was stimulated equally by single or by paired compatible strains of the heterothallic $\boldsymbol{P}$. blakesleeanus. In later experiments other sporing species of the Mucorales were tested and gave similar results. None was as effective as $\boldsymbol{R}$. sexualis itself, but all were more effective than the unrelated Sordaria. 
Rhizoctonia solani, a non-sporing fungus, was also tested as a source. Slide cultures of Rhizopus sexualis grown in the presence of Rhizoctonia solani showed no increase in zygospore production as compared with control cultures which had no source culture present.

Effects of a volatile stimulatory substance produced by mature colonies. Glass cylinders, $2 \mathrm{~cm}$. deep and $3 \mathrm{~cm}$. in diameter, with two glass tubes $3 \mathrm{~mm}$. in diameter, fused into opposite sides as near the top as possible, were sealed by glass plates stuck on to the lower and upper surfaces with silicone grease (Fig. 3). The tubes were plugged with cotton wool and the units could then be autoclaved. The upper glass plate was temporarily removed and $10 \mathrm{ml}$. of molten sterile malt agar medium
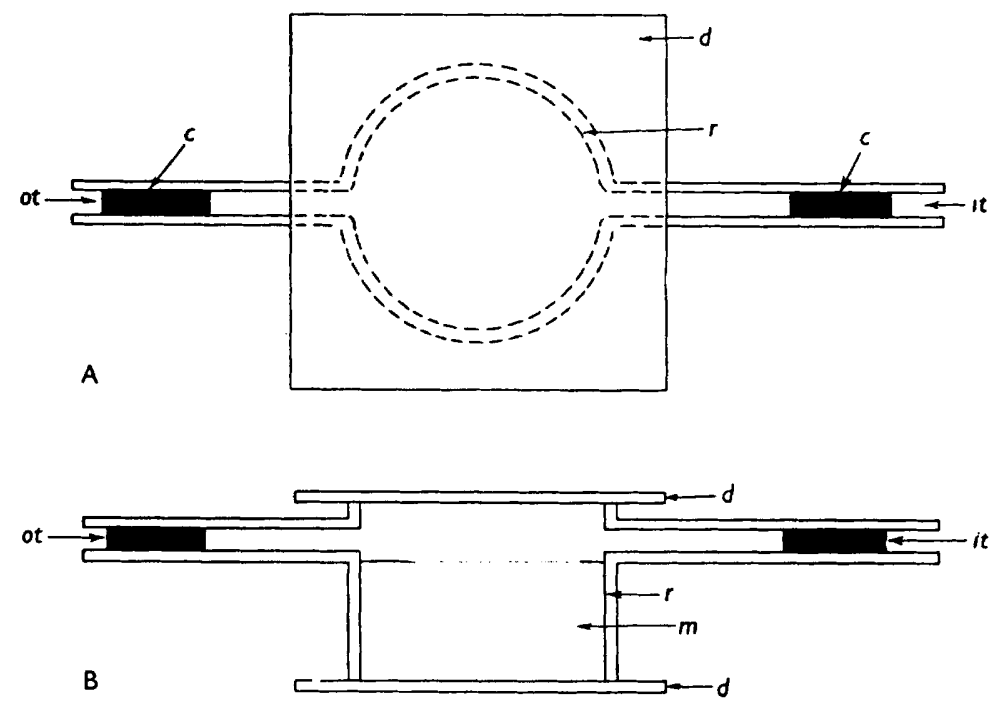

Fig. 3. Vessel designed to allow flow of gas over culture. A, plan and B, elevation of culture vessels used in experiments to test effect of volatile substances from mature cultures on zygospore production of $R$. sexualis. $r=$ glass ring, $i t=$ inlet tube, ot = outlet tube, $c$, cotton-wool plug, $d=$ glass disk sealed to ring (see text), $m=$ agar culture medium.

were allowed to solidify on the bottom of the chamber. A suspension of sporangiospores was then poured over the agar medium and the chamber was rocked until the suspension was evenly distributed over the surface of the agar, after which the glass lid was finally replaced. The inoculated units could be connected together and an air stream passed through the series. The series could be arranged so that the air stream passed over mature cultures (usually growing in large flasks) as source cultures, before passing over young ones (test cultures); the cultures could be maintained at different temperatures so that the air passed from cultures at optimum temperatures over others at low temperatures; the effluent from mature cultures could be scrubbed by passage through various solvents to remove metabolic products likely to be present, or known gases could be passed through the system. The test cultures could be conveniently examined in situ.

In all experiments the source cultures were grown for $48 \mathrm{hr}$. at $20^{\circ}$, by which time zygospores were numerous, before being used. Test cultures were grown at 
$20^{\circ}$ for $24 \mathrm{hr}$., by which time a few young zygospores but no mature ones had developed, or for $48 \mathrm{hr}$. before being treated. Air was then passed from source to test cultures. In the first few experiments the air was passed in continuous flow, but in later ones the total gas space of the system was determined and the air supply was controlled manually in such a way that the air over the source cultures was moved on over the test ones every $4 \mathrm{hr}$., thus allowing a longer period for any volatile product to accumulate over the source colonies and later for it to influence the test colonies. Moreover, this method avoided differences due to slight irregularities in flow rate. The results were more consistent than those with continuous flow but otherwise confirmed them. Control cultures received air which had passed over uninoculated culture medium.

The results of three typical experiments are shown in Table 1. In the first and second of these both source and test cultures were maintained at $20^{\circ}$ and treatment was commenced $24 \mathrm{hr}$. after inoculation of the test culture. The rate of zygospore

Table 1. The effect on zygospore production at $20^{\circ}$ and at $7^{\circ}$ of a stream of air which has previously passed over a mature culture growing at $20^{\circ}$

\begin{tabular}{|c|c|c|c|c|}
\hline $\begin{array}{l}\text { Age of test } \\
\text { culture at } \\
\text { commencement } \\
\text { of treatment }\end{array}$ & $\begin{array}{l}\text { Temperature } \\
\text { at which } \\
\text { test culture } \\
\text { was treated }\end{array}$ & $\begin{array}{l}\text { Treatment of test } \\
\text { cultures* }\end{array}$ & $\begin{array}{l}\text { No. of } \\
\text { replicates } \\
\text { (10 fields } \\
\text { counted in } \\
\text { each) }\end{array}$ & $\begin{array}{l}\text { Av. no. of } \\
\text { zygospores } \\
\text { per } \\
\text { microscopic } \\
\text { field }\end{array}$ \\
\hline $24 \mathrm{hr}$. & $20^{\circ}$ & $\begin{array}{l}\text { Treated } \\
\text { Control } \\
\text { Treated } \\
\text { Control }\end{array}$ & $\begin{array}{r}9 \\
6 \\
8 \\
12\end{array}$ & $\begin{array}{l}75 \\
51 \\
17 \dagger \\
6 \dagger\end{array}$ \\
\hline $48 \mathrm{hr}$. & $7^{\circ}$ & $\begin{array}{l}\text { Treated } \\
\text { Control }\end{array}$ & $\begin{array}{l}6 \\
6\end{array}$ & $\begin{array}{r}10 \\
7\end{array}$ \\
\hline
\end{tabular}

\footnotetext{
* Treated and control cultures received air which had previously passed over mature source cultures and over uninoculated culture media, respectively.

$\dagger$ Only mature zygospores counted in this experiment.
}

production and maturation was greater in the treated than in the control cultures. In the third experiment the test cultures were transferred to $7^{\circ}$ and treatment was begun $48 \mathrm{hr}$. after inoculation. The number of new zygospores initiated and the number of young ones maturing was greater in the treated than in the control cultures. In contrast the number of sporangia was greater in the controls. In a further experiment in which both source and test cultures were transferred to $7^{\circ}$ $48 \mathrm{hr}$. after inoculation there was no stimulatory effect of the source upon the test one. Under these conditions it is likely that the rate of metabolism of the cultures would be so slow that the amount of volatile stimulatory substance produced by the source culture would be negligible, or that the substances would pass over too quickly for the test colonies to use it.

It is thus clear that some volatile product of metabolism stimulated zygospore development and that an adequate supply of it from external sources counteracted the inhibitory effect of low temperature. One must conclude that this inhibitory effect was at least partially due to failure of the fungus to synthesize the unknown volatile product at the low temperature. 
Possible nature of the volatile stimulatory substance. The observation that cultures of Rhizoctonia solani do not produce volatile substances capable of stimulating zygospore production by Rhizopus indicates that the active factor is unlikely to be a common metabolic product, such as carbon dioxide, ammonia or ethanol. Moreover, no increase in zygospore production resulted when carbon dioxide or ammonia, at concentrations permitting vegetative growth, were passed over a young culture in a chamber of the type described in the previous section. The removal of carbon dioxide or ammonia, by passage through traps placed between source and test cultures and containing $20 \%$ aqueous potassium hydroxide or Nessler's reagent, respectively, did not alter the activity of the effluent. Ethanol (70\% aqueous) placed between source and test cultures also failed to influence zygospore formation. Thus it is clear that none of these substances is the cause of the stimulatory effect.

Passage of the effluent through dilute sulphuric acid removed the activity, even when the humidity was restored by subsequent passage through water. This indicates that the substance is probably basic. Titration of the acid against $0.01 \mathrm{~N}-$ $\mathrm{NaOH}$, however, did not show any change in the titration value; any substance removed by the acid must have been present in very small quantities.

Hepden \& Folkes (1960), in considering the possible relationship between nucleic acid metabolism and the initiation of zygospores, suggest that the volatile substance is likely to be a methyl donor. They discuss the possibility that this might be methylamine and outline a probable mechanism for its action. The removal of the stimulatory effect of gaseous effluent from mature cultures of Rhizopus by passage through acid is consistent with methylamine being at least partially effective. Accordingly a number of methyl donors and other methylated compounds were tested for their effects on Rhizopus sexualis.

In some experiments these substances were incorporated in glucose-asparagine agar, glucose-ammonium salts agar or $1 \%$ malt agar, to which they were added when they were cooling. In others compounds were placed on disks of filter paper which were laid directly on the agar plate or were placed on sterile glass coverslips which were then laid on the medium. In another series of experiments, Rhizopus sexualis was grown on glass microscope slides in a film of liquid culture medium. The nonvolatile substances to be tested were added to this liquid; the volatile ones were placed in Petri dishes and the test slide cultures were supported above them. Both plate and slide cultures were tested at $20^{\circ}$ and at $7^{\circ}$, to which they were transferred after $24 \mathrm{hr}$. at $20^{\circ}$. The results of all these experiments are collected in Table 2.

All the methyl donors tested were either ineffective or were more or less toxic even at low concentrations. None of them induced an increase in zygospore initiation and maturation comparable to that shown in Table 1 as resulting from the volatile substances produced by mature cultures. Choline, methylamine, DL-serine, formaldehyde, formic acid and methanol showed some counteraction of the effect of low temperature on cultures which had already begun to form zygospores before transfer to $7^{\circ}$. None of these substances, however, significantly increased the number of zygospores developing in cultures which, at the time of transfer to low temperature, bore no mature zygospores. In all cultures there was an increase in the number of pseudophores which, as already pointed out, have been interpreted 


\section{Zygospore formation in Rhizopus}

as potential progametangia and which, under suitable conditions, sometimes develop into azygospores. Callen (1940) reported an increase in the number of pseudophores produced by Rhizopus sexualis in the presence of the related $\boldsymbol{R}$. nigricans. It is thus possible that the production of pseudophores indicates activity comparable to that of the naturally produced volatile substance, but that the beneficial effects are counteracted by the toxic nature of the pure compounds. Concentrations of these pure substances too low to be toxic had no effect on the production of pseudophores or of normal zygospores. These results do not exclude the possibility that the active substance is methylamine or some other methyl-donor.

Table 2. Effects of various methyl donors and methylated compounds on growth and zygospore formation at $20^{\circ}$ and at $7-10^{\circ}$ after $24 \mathrm{hr}$. at $20^{\circ}$

\begin{tabular}{|c|c|c|c|c|c|c|}
\hline \multirow[b]{2}{*}{ Substance } & \multirow[b]{2}{*}{$\begin{array}{c}\text { Percentage } \\
\text { concentration }\end{array}$} & \multirow[b]{2}{*}{$\begin{array}{c}\text { Method } \\
\text { of } \\
\text { supply }\end{array}$} & \multicolumn{2}{|c|}{ Effects at $20^{\circ}$} & \multicolumn{2}{|c|}{ Effects at $7-10^{\circ}$} \\
\hline & & & $\begin{array}{c}\text { On } \\
\text { growth }\end{array}$ & $\begin{array}{c}\text { On } \\
\text { zygospore } \\
\text { formation }\end{array}$ & $\begin{array}{c}\text { On } \\
\text { growth }\end{array}$ & $\begin{array}{c}\text { On } \\
\text { zygospore } \\
\text { formation }\end{array}$ \\
\hline Methionine & $0.1-0.2$ & A & None $^{1}$ & None & + & None \\
\hline Methylamine & $7 \cdot 0-70 \cdot 0$ & B, C D &,$- p$ & None & \pm & $\mathbf{p}$ \\
\hline Methylamine. HCl & $0 \cdot 1$ & $\mathbf{A}$ & - & None & \pm & $\mathbf{p}$ \\
\hline Methanol & $10-100$ & C, D & - & $\mathbf{p}$ & None & $\mathbf{p}$ \\
\hline Thymine & $0 \cdot 1$ & A & None & None & None & None \\
\hline Choline chloride & $0.001-1.0$ & $\mathbf{A}$ & \pm & None & \pm & ++ \\
\hline Formaldehyde & $0.08-0.64$ & A, D & \pm & -2 & \pm & $\mathrm{p}$ \\
\hline Formic acid & $0.09-0.46$ & $\mathbf{B}, \mathbf{D}$ & - & $\mathrm{p}$ & - & $\mathrm{p}$ \\
\hline Glycine & $0.01-0.1$ & $\mathbf{A}$ & None & None & None & None \\
\hline DL-Serine & $0 \cdot 01-0 \cdot 1$ & $\mathbf{A}$ & + & + & None & ++ \\
\hline Betaine. $\mathrm{HCl}$ & $0.01-0.1$ & $\mathbf{A}$ & None & None & None & None \\
\hline
\end{tabular}

\section{Key to Table 2}

A, incorporated in culture medium.

$B$, on paper disk laid on agar medium.

C, on glass coverslip laid on agar medium.

$\mathrm{D}$, on dish with slide culture supported above.

+ , slight increase.

++ , increase.

- , decrease.

\pm , slight increase or decrease according to concentration.

$\bar{p}$, increase in number of pseudophores or of irregular swellings resembling pseudophores.

${ }^{1}$, slight increase in absence of other source of nitrogen.

${ }^{2}$, pseudophores developed in slide cultures only.

\section{DISCUSSION}

The experiments show that a volatile substance or substances produced by matu? cultures of Rhizopus sexualis stimulates zygospore production by young cultures of the same fungus at optimal temperatures $\left(c .20^{\circ}\right)$ and partially counteracts the inhibitory effects of low temperatures $\left(7-10^{\circ}\right)$. It is established that the active factor in the effluent gases is not carbon dioxide, ammonia or ethanol, that it is basic and probably produced in extremely small quantities. The identity of the active substance has not been established but the experimental results are not inconsistent with its being methylamine. It is clear, however, that the effects of the naturally produced substance cannot be exactly reproduced by low concentrations of pure methylamine. 
The effects of the presence of cultures of related species were less than those of mature cultures of Rhizopus sexualis itself, and the unrelated Sordaria was even less effective. It is possible, therefore, that the activity of the effluent from mature cultures is not due to a single volatile substance but to a mixture of several such substances. The exact composition and proportions of such a mixture might well vary with different species, thus accounting for the high degree of specificity observed and the decreasing effect on $R$. sexualis with decrease in the relationship between test and source cultures. It is thus unlikely that volatile substances stimulating other fungi are exactly identical with that produced by $\boldsymbol{R}$. sexualis. Of such substances, an unidentified one described by Banbury (1954) as stimulating zygotropism in Mucor hiemalis might conceivably be of similar nature; one described by Mc'Teague, Hutchinson \& Reed (1959) as stimulating growth of germ tubes of Agaricus campestris and identified as 2-3-dimethylpentene is unlikely to resemble closely that produced by $R$. sexualis. It is hoped that further work now in progress may establish the nature of the latter and elucidate the part that it plays in zygospore initiation.

We wish to thank Dr B. F. Folkes and other colleagues at the University of Bristol and at Imperial College, London, for advice on the chemical aspects of this investigation. Most of this work was done while the junior author (P.M.H.) was in receipt of a training grant from the D.S.I.R. to which her thanks are due.

\section{REFERENCES}

Banbury, G. H. (1954). Physiological studies in the Mucorales. III. The zygotropism of zygophores of Mucor mucedo Brefeld. J. exp. Bot. 6, 235.

Callen, E. O. (1940). Morphology, cytology and sexuality of the homothallic Rhizopus sexualis (Smith) Callen. Ann. Bot., Lond. N.S. 4, 791.

Hawker, L. E. (1957). The Physiology of Reproduction in Fungi. Cambridge Monographs in Experimental Biology. Cambridge University Press.

Hawker, L. E., Hepden, P. M. \& Perkins, S. M. (1957). The inhibiting effect of low temperature on early stages of zygospore production in Rhizopus sexualis. J. gen. Microbiol. 17, 758.

Hepden, P. M. \& Folkes, B. F. (1960). A possible relationship between nucleic acid metabolism and the initiation of zygospores of Rhizopus sexualis. Nature, Lond. 185, 254.

McTeague, D. M., Hutchinson, S. A. \& Reed, R. I. (1959). Spore germination in Agaricus campestris L. ex. Fr. Nature, Lond. 183, 1736.

Robbins, W. J. \& Kavanagh, F. (1942). Hypoxanthine, a growth substance for Phycomyces. Proc. nat. Acad. Sci., Wash. 28, 65. 